\section{JTI}

JOURNAL OF

TRAUMA AND INJURY

\title{
The Management of Open Pelvic Fractures: A Report of 2 Cases
}

\author{
Byungchul Yu, M.D. ${ }^{1,2}$, Gil Jae Lee, M.D., Ph.D. ${ }^{1,2}$, Min A Lee, M.D. ${ }^{1,2}$, \\ Kangkook Choi, M.D. ${ }^{1,2}$, Jihun Gwak, M.D. ${ }^{1}$, Youngeun Park, M.D. ${ }^{1}$, \\ Yong-Cheol Yoon, M.D. ${ }^{1,2}$ Jungnam Lee, M.D. ${ }^{1,2}$ \\ ${ }^{1}$ Department of Trauma Surgery, Gachon University Gil Medical Center, Incheon, Korea \\ ${ }^{2}$ Department of Traumatology, Gachon University College of Medicine, Incheon, Korea
}

Received: March 4, 2020

Revised: March 31, 2020

Accepted: April 9, 2020

Correspondence to

Jungnam Lee, M.D.

Department of Traumatology, Gachon University Gil Medical Center, 21

Namdong-daero 774beon-gil, Namdong-gu, Incheon 21565, Korea

Tel: $+82-32-460-3010$

Fax: +82-32-460-3247

E-mail:jnlee@gilhospital.com
Open pelvic fractures are rare, but pose challenges for trauma surgeons due to their high morbidity and mortality. Generally, early death results from uncontrolled exsanguination and late death is related to pelvic sepsis. Therefore, management of these injuries should prioritize hemostasis and contamination control starting in the initial phase of treatment. We report two cases of unstable open pelvic fractures with perineal wounds that were managed successfully.

Keywords: Trauma, Trauma centers, Pelvic bones, Fractures

\section{INTRODUCTION}

Open pelvic fractures are rare and account for only $2-4 \%$ of all pelvic fractures $[1,2]$. These fractures are characterized by a direct communication between the bony injury and the overlying skin, rectum, or vagina. Owing to the high energy of the underlying injury mechanism, associated injuries are common, and the mortality rate of patients with open pelvic fractures is higher than that of patients with pelvic fractures without an open wound [3]. Usually, early death is related to exsanguination, while late death occurs as a consequence of pelvic sepsis. Hence, the management strategy should focus on the control of bleeding and contamination, starting at the initial phase. We report two cases of open pelvic fractures with perineal injuries (Faringer zone I) and review the management of these injuries. 


\section{JTI}

\section{CASE REPORT}

\section{Case 1}

A 27-year-old man was transported to the regional trauma center following a motorbike accident. On arrival, the patient's blood pressure was $99 / 60 \mathrm{mmHg}$, his pulse rate was 130 beats per minute (bpm), and his Glasgow Coma Scale score was 15. A large and deep laceration in the perineum was noted, as well as several bilateral lacerations in the lower extremities (Fig. 1). The patient's initial base deficit (BD) and lactate levels were $8.3 \mathrm{mmol} / \mathrm{L}$ and
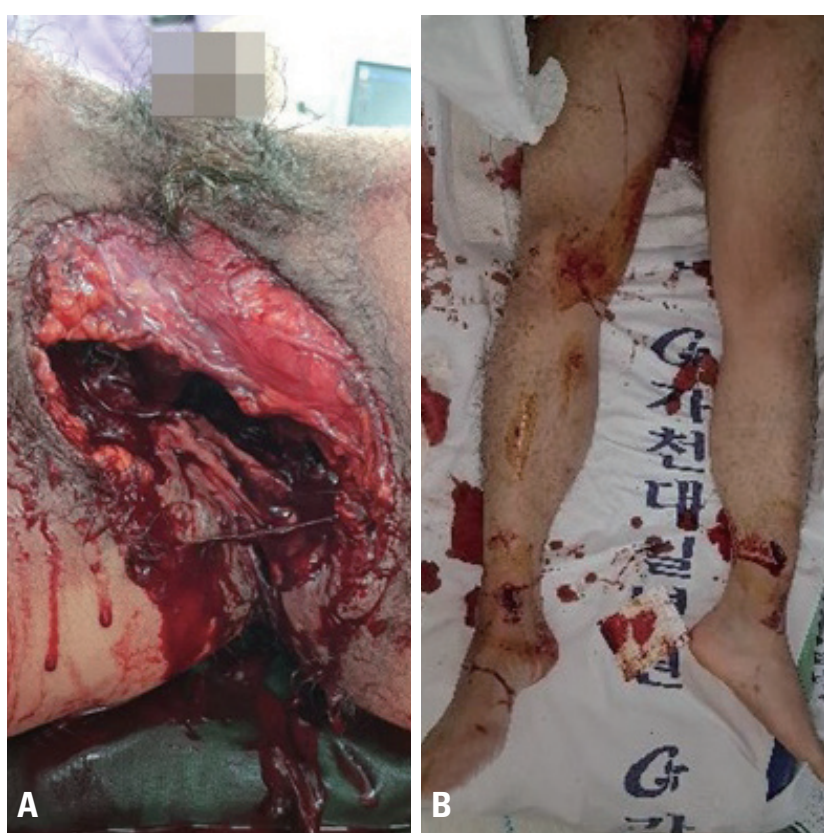

Fig. 1. (A) Deep perineal laceration and (B) deformity and lacerations of both legs.
$4.2 \mathrm{mmol} / \mathrm{L}$, respectively. Ultrasonography did not reveal free fluid in the abdominal cavity. The patient's systolic blood pressure (SBP) increased to $124 \mathrm{mmHg}$ after resuscitation, perineal wound packing, and application of a pelvic binder. He underwent whole-body computed tomography (CT), and CT scans of the head, cervical spine, and chest showed no definite injury. Pelvic X-ray and abdominopelvic CT revealed fluid collection, free air in the peritoneal cavity, and a Young and Burgess APC type III fracture with massive soft tissue injuries (Fig. 2). He was taken to the operating room for laparotomy, pelvic packing, and urologic procedures.

Upon performing midline laparotomy, a liter of blood was found in the abdominal cavity, and 2 small bowel perforations and rupture of the mesentery were also seen. Small bowel resection and anastomosis and transverse colostomy were performed. After laparotomy closure, we initiated perineal wound exploration, which revealed injuries to the rectum, urethra, and bladder, along with scrotal herniation. Repair of the urethra and bladder could not be performed owing to extensive injury and bleeding; hence, percutaneous nephrostomy was performed. After performing gauze packing through the perineal wound, the patient was moved to the intensive care unit (ICU). His systolic blood pressure was $160 \mathrm{mmHg}$ and $\mathrm{BD}$ was $5.2 \mathrm{mmol} / \mathrm{L}$. At this point, the patient received a total of 18 units of packed red blood cells (PRBCs) and 14 units of fresh frozen plasma (FFP). His duration of stay in the emergency room was 125 minutes, and the total time for the operative procedure was 375 minutes.

We performed debridement of the rectum and sigmoid colostomy with take-down of the previous transverse
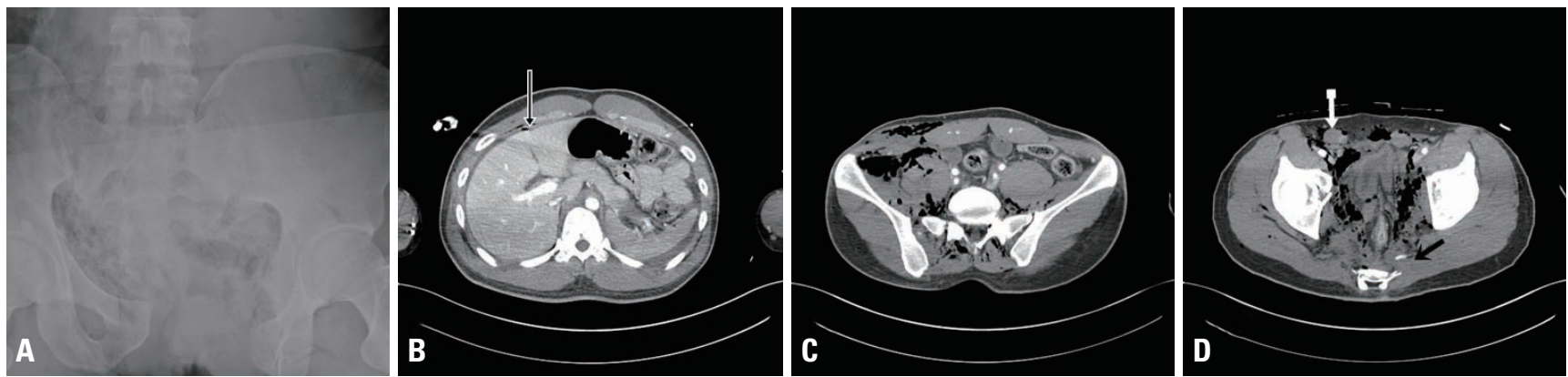

Fig. 2. (A) Pelvic X-ray and computed tomography (CT) scan. Pelvic X-ray shows an APC type III fracture. (B) CT scan shows fluid collection and free air (black arrow), (C) extensive soft tissue injuries (D) dislocation of the testicle (white arrow), and contrast leakage (black arrow). 
colostomy the next day. Subsequently, irrigation and debridement was performed every alternate day, and the
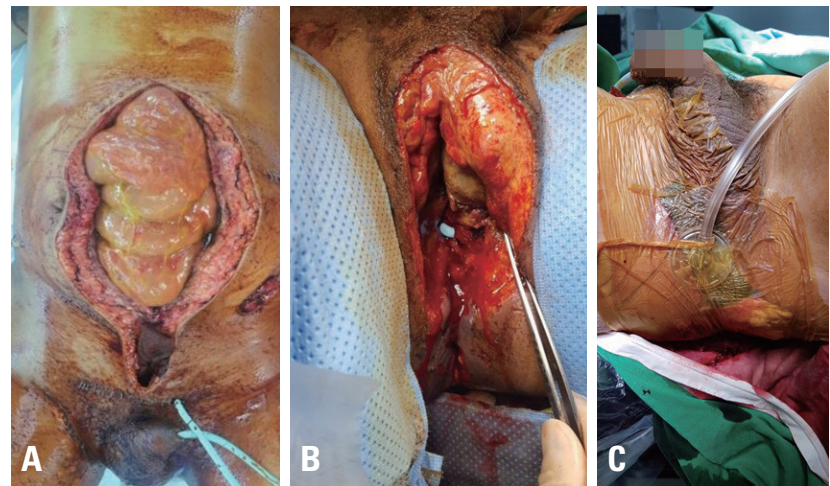

Fig. 3. Second surgery on day 2. (A) Sigmoid colostomy and open vesicostomy were performed. (B) Transection of the urethra was seen. (C) Negative-pressure wound therapy was performed for perineal wound care.
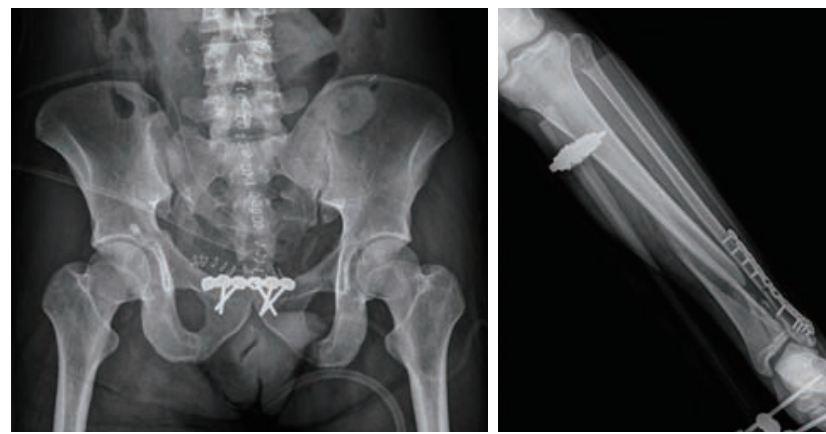

Fig. 4. X-rays after bone stabilization. perineal wound was managed with negative-pressure wound therapy (NPWT) (Fig. 3). Six days after admission, he underwent definitive internal and external fixation of the pelvic and tibiofibular fractures (Fig. 4). He was connected to a mechanical ventilator for 8 days, and the ICU stay was 14 days. He was discharged home with a permanent colostomy and vesicostomy after 138 days of admission (Fig. 5). We started a third-generation cephalosporin initially, which was shifted to piperacillin/tazobactam on hospital day 7. On the 14th day of admission, the antibiotic prescription was shifted to a first-generation cephalosporin.

\section{Case 2}

A 50-year-old woman was brought to the regional trauma center by ambulance directly from the scene of a pedestrian traffic accident. On arrival, her SBP was $77 \mathrm{mmHg}$, her pulse rate was $144 \mathrm{bpm}$, and she had an alert mental status. Her initial BD and lactate levels were $1.5 \mathrm{mmol} / \mathrm{L}$ and $6.3 \mathrm{mmol} / \mathrm{L}$, respectively. She had a large perineal laceration, and an anteroposterior pelvic X-ray showed a Young and Burgess LC type III pelvic fracture (Fig. 6). Ultrasonography did not reveal free fluid in the abdominal cavity. The patient was resuscitated with fluids and transfusion and was moved to the CT room to undergo abdominopelvic CT. Subsequently, she was transported to the operating room (OR) directly from the CT room 70 minutes after her arrival. In the OR, rupture of the anal sphincter, anal laceration, and tears of the pelvic muscles
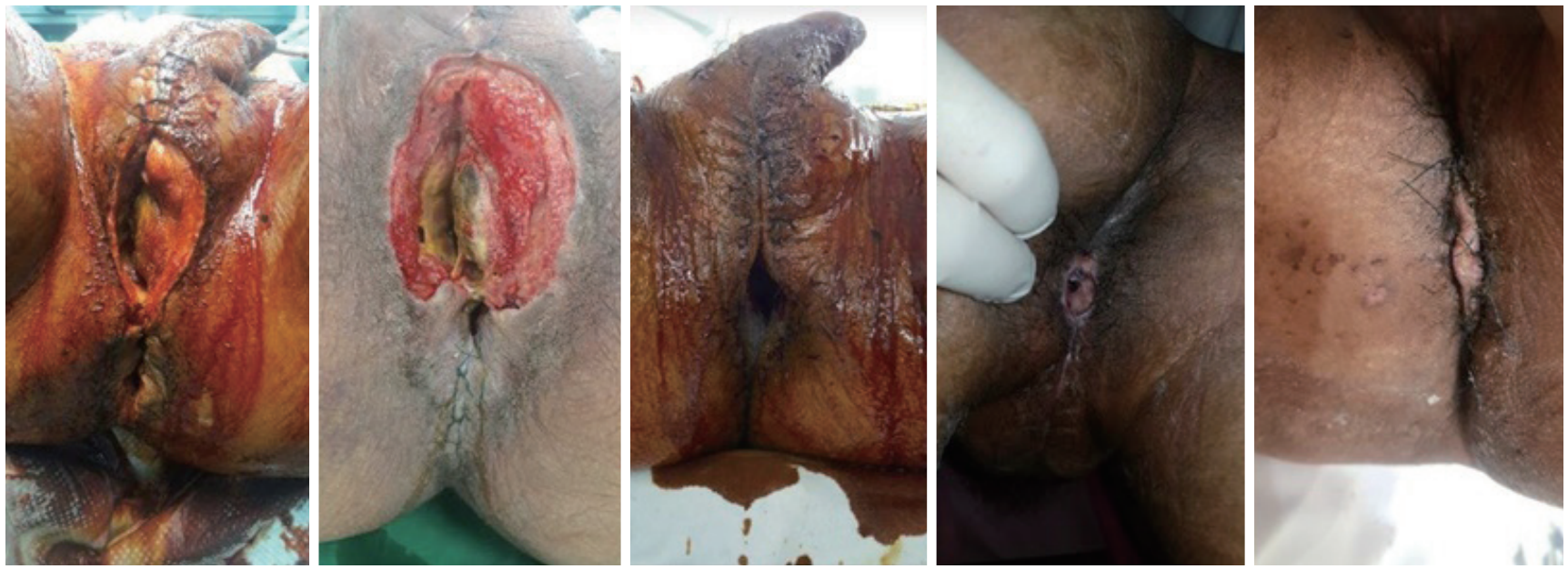

Fig. 5. Serial images of perineal wound healing. There was minimal anal discharge from the anus and from the skin defect; it was completely closed eventually (at 104 days from admission). 


\section{JTI}

were noted; active bleeding from the wound was also seen. Bleeder ligation and pelvic packing through the wound were performed. The total time required for the procedure was 20 minutes (Fig. 7), after which the patient's SBP was $86 \mathrm{mmHg}$ and pulse rate was $126 \mathrm{bpm}$. We suspected arterial bleeding in the pelvis; hence, the patient was transported to the interventional radiology suite directly from the OR. Embolization of branches of the internal iliac and deep femoral arteries was performed. The total time for angioembolization was 115 minutes. She received 6 units of PRBCs and no FFP until then. Subsequently, the patient was transferred to the trauma ICU, with an SBP of more than $100 \mathrm{mmHg}$. She was administered 6 units of PRBCs and 12 units of FFP within 24 hours after arrival.

The next day, the patient was moved to the OR, where perineal wound debridement, removal of the packing, sphincter and anus repair, NPWT, and loop transverse colostomy were performed (Fig. 7). Eight days after admission, open reduction and internal fixation of the pelvic fracture were performed (Fig. 8). On the same day, we noticed extensive skin and soft tissue necrosis over the buttock area. The necrotized skin and soft tissue were removed, and meticulous debridement was performed (Fig. 8). NPWT was performed for the perineal and buttock wounds, and the patient was taken to the OR twice a week (Fig. 8). At 34 and 63 days after admission,

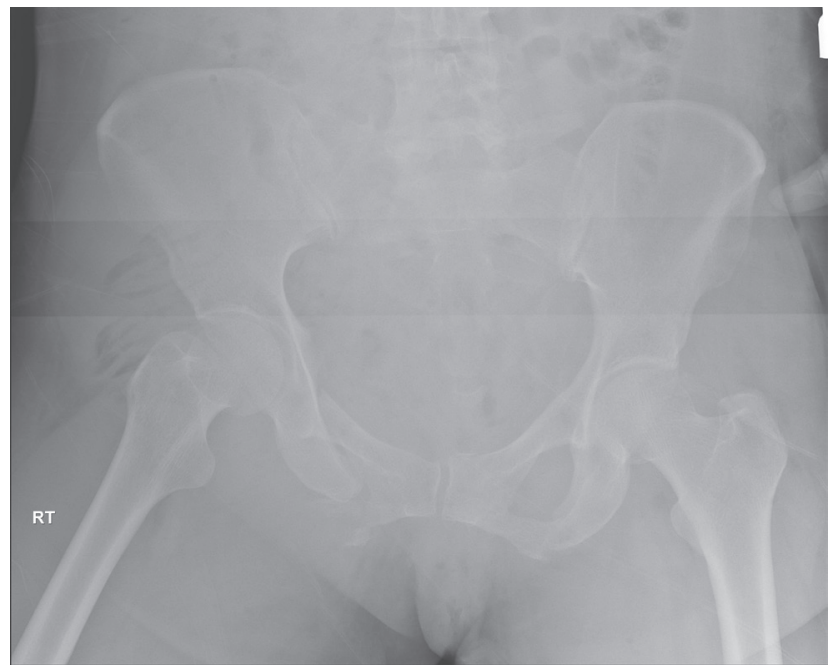

Fig. 6. Pelvic X-ray at the trauma bay. split-thickness skin grafting was performed, and she was subsequently discharged to a rehabilitation facility. She was able to walk with the support of a walker (Fig. 9). The ICU stay was 21 days, and the total hospital stay was 110 days. We started a third-generation cephalosporin initially, which was shifted to piperacillin/tazobactam on hospital day 4. On the 16th day of admission, the antibiotic prescription was shifted to imipenem because of an Escherichia coli bloodstream infection.

\section{DISCUSSION}

Management of open pelvic fractures is a challenge for trauma surgeons owing to their high morbidity and mortality rates, the latter of which can reach $24-45 \%$ [3-5]. In particular, open pelvic fractures associated with vaginal or rectal laceration and Faringer zone I injuries have a high risk of infection and mortality [6]. As seen in our cases, open pelvic fracture is associated with the need for large-volume blood transfusion, long hospital stays, and high costs of care [3]. Early mortality is related to exsanguination, while late mortality is related to sepsis and multi-organ failure. Therefore, the management priorities in the initial phase should focus on urgent control of bleeding using available options such as laparotomy, packing, bleeder ligation, bone stabilization, and interven-
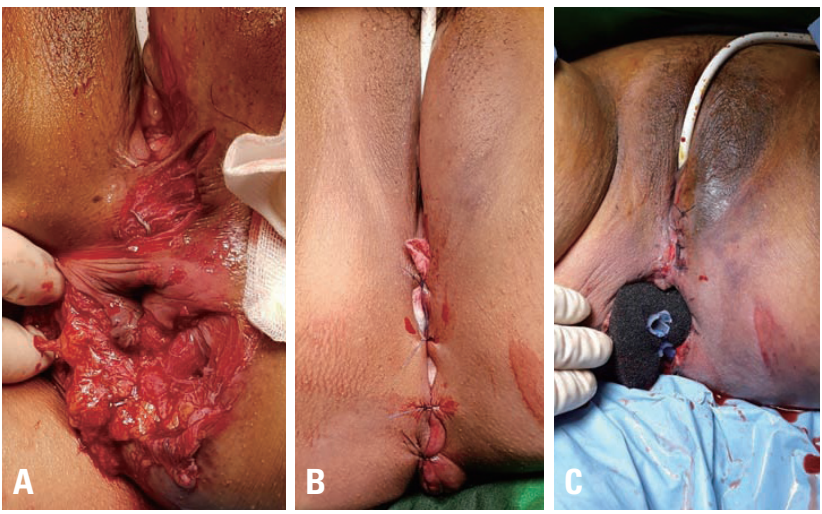

Fig. 7. Perineal wound. (A) A deep perineal wound with internal sphincter rupture and bleeding without a rectal injury were noted. (B) Gauze packing through the perineal wound was performed. (C) The next day, debridement, sphincter repair, wound repair, and negative-pressure wound therapy were performed. 

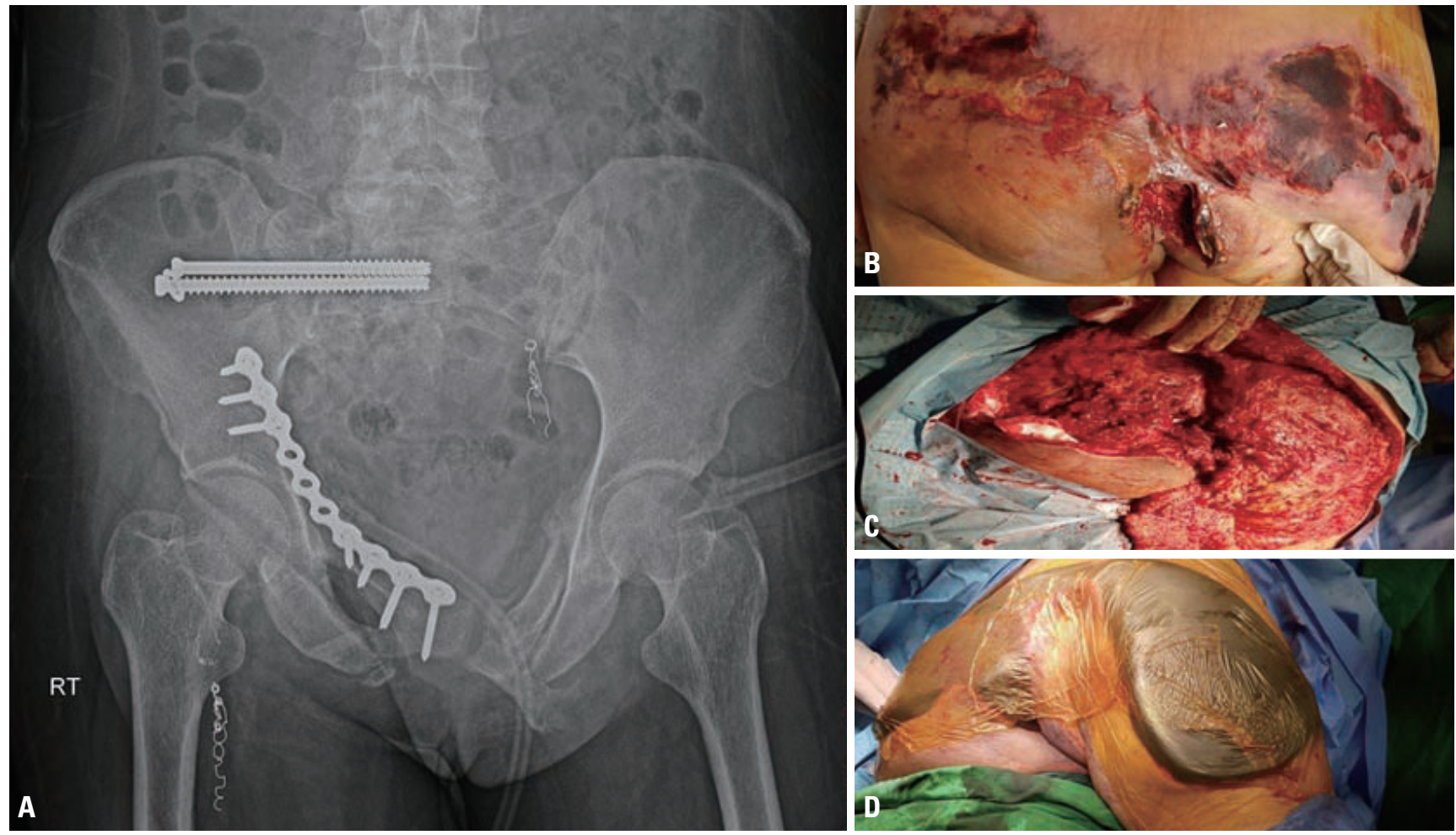

Fig. 8. Pelvic X-ray and buttock wound. (A) Pelvic anteroposterior X-ray after definitive fixation. (B) Skin and soft tissue necrosis of the buttock. (C) Extensive debridement of the necrotized tissue. (D) Negative-pressure wound therapy was performed for the buttock wound.
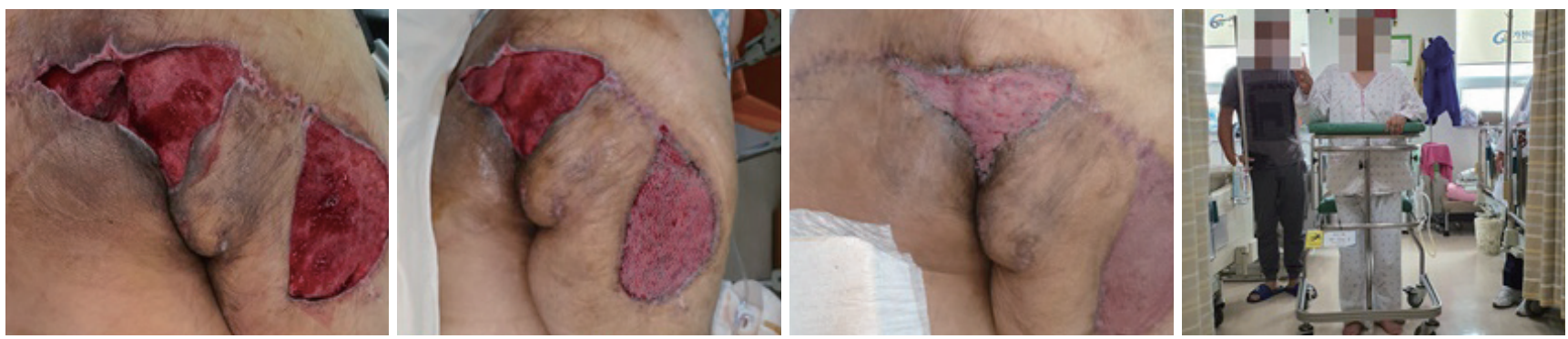

Fig. 9. Buttock wound management. Serial split-thickness skin grafting was performed, and the patient was able to walk with help when she was transported to a rehabilitation facility.

tional radiology. The concept of damage control resuscitation should be followed. An attempt at early diagnosis of rectal and/or urogenital injuries is important.

The selective use of fecal diversion in open pelvic fractures has been well established in the literature [6-8]. Repeated wound irrigation and debridement, adequate drainage, and distal rectal washout and rectal injury repair can prevent pelvic sepsis. Most authors suggest that an open pelvic fracture with a zone I wound is an appropri- ate indication for fecal diversion [9-11]. Hence, the strategy at our facility is mandatory fecal diversion for a zone I wound and selective diversion for a zone II or III injury. Traditionally, loop colostomy was used as a standard procedure, but loop ileostomy also can be an appropriate option for fecal diversion. Both procedures have several advantages and disadvantages, but did not show any differences in outcomes [12]. In practice, we favor using loop colostomy and avoid sites that might be required for 
orthopedic incisions, external fixator pins, and vesicostomy when choosing the location for a stoma.

In open fractures, the timing of definitive fixation of the pelvic ring is not clearly established in the available literature. Some authors suggest that the condition of the soft tissue and the physiological status of the patient are important factors affecting the decision-making process [13]. The ideal fixation technique for open fractures remains controversial. Traditionally, external fixation has been considered the only option for these patients [14]. However, other authors have reported good functional results and low complication rates using internal fixation, with meticulous soft tissue management [15]. Internal fixation can be performed in patients with no gross contamination in the region of the fracture, while external fixation is preferred in situations of fecal contamination of the fracture site. Both our patients were stabilized with internal fixation without related complications.

In summary, early bleeding control and appropriate contamination control, including fecal diversion and meticulous debridement of soft tissue, as part of a multidisciplinary approach with appropriate leadership are the critical cornerstones of the management of unstable zone 1 open pelvic fractures.

\section{REFERENCES}

1. Grotz MR, Allami MK, Harwood P, Pape HC, Krettek C, Giannoudis PV. Open pelvic fractures: epidemiology, current concepts of management and outcome. Injury 2005;36:1-13.

2. Bircher M, Hargrove R. Is it possible to classify open fractures of the pelvis? Eur J Trauma 2004;30:74-9.

3. Dente CJ, Feliciano DV, Rozycki GS, Wyrzykowski AD, Nicholas
JM, Salomone JP, et al. The outcome of open pelvic fractures in the modern era. Am J Surg 2005;190:830-5.

4. Dong Jl, Zhou DS. Management and outcome of open pelvic fractures: a retrospective study of 41 cases. Injury 2011;42:1003-7.

5. Hanson PB, Milne JC, Chapman MW. Open fractures of the pelvis. Review of 43 cases. J Bone Joint Surg Br 1991;73:325-9.

6. Lunsjo K, Abu-Zidan FM. Does colostomy prevent infection in open blunt pelvic fractures? A systematic review. J Trauma 2006;60:1145-8.

7. Faringer PD, Mullins RJ, Feliciano PD, Duwelius PJ, Trunkey DD. Selective fecal diversion in complex open pelvic fractures from blunt trauma. Arch Surg 1994;129:958-63; discussion 963-4.

8. Petrone P, Inaba K, Wasserberg N, Teixeira PG, Sarkisyan G, Dubose JJ, et al. Perineal injuries at a large urban trauma center: injury patterns and outcomes. Am Surg 2009;75:317-20.

9. Brenneman FD, Katyal D, Boulanger BR, Tile M, Redelmeier DA. Long-term outcomes in open pelvic fractures. J Trauma 1997;42:773-7.

10. Fallon WF. The present role of colostomy in the management of trauma. Dis Colon Rectum 1992;35:1094-102.

11. Sola JE, Bender JS, Buchman TG. Morbidity and timing of colostomy closure in trauma patients. Injury 1993;24:438-40.

12. Law WL, Chu KW, Choi HK. Randomized clinical trial comparing loop ileostomy and loop transverse colostomy for faecal diversion following total mesorectal excision. Br J Surg 2002;89:704-8.

13. Grotz MR, Allami MK, Harwood P, Pape HC, Krettek C, Giannoudis PV. Open pelvic fractures: epidemiology, current concepts of management and outcome. Injury 2005;36:1-13.

14. Tang P, Meredick R, Prayson MJ, Gruen G. External fixation of the pelvis. Tech Orthop 2002;17:228-38.

15. Leenen LP, van der Werken C, Schoots F, Goris RJ. Internal fixation of open unstable pelvic fractures. J Trauma 1993;35:220-5. 